\title{
Teachers’ Transformation to Inquiry-Based Instructional Practice
}

\author{
Jeff C. Marshall ${ }^{1}$, Julie B. Smart ${ }^{2}$ \\ ${ }^{1}$ School of Education, Clemson University, Clemson, USA \\ ${ }^{2}$ Presbyterian College, Clinton, USA \\ Email: marsha9@clemson.edu
}

Received December $6^{\text {th }}$, 2012; revised January $8^{\text {th }}$, 2013; accepted January $21^{\text {st }}, 2013$

\begin{abstract}
This collective case study examines secondary science teachers' responses to a professional development program designed to assist in the transformation of inquiry belief structures and inquiry instructional practices. These teachers were participants in a year-long professional development institute that focused on increasing the quantity and quality of inquiry in secondary science classrooms. This multi-case design examines multiple data sources in order to answer the following research question: How do the beliefs and practices of teachers regarding inquiry-based instruction evolve over the year of intervention? Participants were selected using the data from an inquiry observational protocol to represent a variety of abilities and beliefs regarding inquiry instructional practice. The results provide insights into teachers' belief structures and classroom structure related to inquiry instruction. Further, we detail the role of the professional development experience in facilitating transformation of classroom practice. Implications for how professional development programs are developed and led are provided.
\end{abstract}

Keywords: Beliefs; Collective Case Study; Conceptions; Instructional Methods; Inquiry-Based Instruction; Inquiry Instruction; Science Education; Teacher Transformation; Transition in Practice

\section{Introduction}

With years of counterexamples to guide their own learning, science teachers often find it difficult to transform their instruction to more inquiry-based practice. Reform documents such as the National Science Education Standards, NSES, have defined inquiry-based practice (National Research Council, [NRC], 1996) and articulated what it looks like compared to non-inquiry approaches (Llewellyn, 2005, 2000). Yet, the goal of high-quality, frequent inquiry-based instruction in science classrooms is far from being achieved. Further, professional development (PD) experiences have largely fallen short of the desired transformation in practice (Bybee et al., 2006, 2000). Part of the challenge exists because multiple viewpoints seem to exist for how inquiry-based instruction should be implemented in the classroom. Anderson notes, NSES (NRC, 1996) leaves readers to create their own image of inquiry-based instruction (Anderson, 2002). Paradoxically, we are left with an inquiry challenge regarding inquiry-based instruction.

Other reasons why teachers may have difficulty successfully implementing inquiry-based instruction include: 1) difficulty "creating a science classroom that causes students to be perplexed without being overly confused” (McDonald, Criswell, \& Dreon, 2008: p. 42); 2) lack of linearity found in other methods; and (3) insufficient time to unravel the complexities and ambiguities inherent to inquiry. Despite the challenges, many opportunities exist for teachers to scaffold instruction so that learning improves, thus addressing the multifaceted and complex nature of inquiry (Vanosdall, Klentschy, Hedges, \& Weisbaum, 2007; Windschitl, 2008).

Our study focuses on teacher implementation of content-rich inquiry-based instruction where state and national science content standards are explicitly linked with inquiry-based practice. Specifically, how do the beliefs and practices of teachers re- garding inquiry-based instruction evolve over the course of a year-long professional development (PD) program?

\section{Theoretical Framework}

\section{Transformation of Practice via Professional Development Experiences}

In order to achieve transformation of practice, PD programs need to be grounded, aligned, and implemented based on solid research findings. The proposed research question seeks to examine whether the expressed beliefs of experienced science and math teachers are consistent with their practice in the classroom (Van Driel, Beijaard, \& Verloop, 2001). Some have suggested that changing beliefs is necessary but not always sufficient for changing practice (Briscoe, 1991; Johnston, 1991; Mellado, 1998). PD programs that seek to achieve a belief structure that mirrors actual practice often share three common themes: 1) requires that participants engage in long-term sustained involvement; 2) must be context-embedded; and 3) must be content focused (Garet, Porter, Desimone, Birman, \& Yoon, 2001; Guskey, 2003; Smylie, Allensworth, Greenberg, Harris, \& Luppescu, 2001; Supovitz \& Turner, 2000).

Time. First, considerable time is required, both in duration and quantity, to build from current conceptions to a transformed, sustained inquiry-based practice. While exact agreement has not been reached on the quantity and duration of PD necessary to promote transformation of practice, research indicates that at least 80 hours of engaged, participant involvement that extends throughout at least one academic year is optimal (Garet et al., 2001; Loucks-Horsley, Love, Stiles, Mundry, \& Hewson, 2003; Supovitz \& Turner, 2000).

Context and Environment. Sufficient time provides one cornerstone, but how the time is spent is equally critical to encouraging transformation. Specifically, properly addressing the 
context and environment help to facilitate transformation by building on existing experiences. For effective PD, teachers must interact in ways that bring their own learning context and prior experiences into the transformative experience. Specifically, more reformed ideas of PD provide personalized social networks for teachers to interact with others, peer coaching opportunities, and case studies. These interactions and experiences need to be embedded in ways that are directly transferable to their classroom context and environment (Garet et al., 2001; Lumpe, Haney, \& Czerniak, 2000).

Content-focused. Content specificity of the PD experience is critical. In science, this often requires that participants understand and begin to shift belief structures away from their more common positivist views of science, in which science is fixed and unchangeable, to an understanding that science is complex, often tentative, and a continually growing field (Abd-ElKhalick \& BouJaoude, 1997). When teachers are engaged in the content and curriculum that is critical to their own classrooms through modeling, cases studies, and various other methods, they are more likely to begin to transform their practice (Van Driel, et al., 2001). Further, reform documents in science have suggested that greater emphasis needs to be placed on inquiry-based forms of instruction that require students to think deeper and more critically about learning. To be clear,

Inquiry is a multifaceted activity that involves making observations; posing questions; examining... sources of information...; planning investigations; reviewing... evidence; using tools...; proposing answers, explanations, and predictions; and communicating results. Inquiry requires identification of assumptions, use of critical and logical thinking, and consideration of alternative explanations (NRC, 1996: p. 23).

Despite this detailed definition, inquiry is still inconsistently applied in the classroom. Specifically, teachers often confuse teaching science by inquiry with teaching science as inquiry (Chiappetta \& Koballa, 2006). The prevalent, teaching by inquiry, results in an "activity-mania" of short, often disconnected, entertaining activities at the expense of "minds-on" content-laden inquiry investigations (Moscovici \& HoldlundNelson, 1998). A more desirable teaching science as inquiry fuses content and process, thus resulting in scientific inquiry. The need to separate "learning content" from "doing inquiry" is unnecessary (Windschitl, 2008).

\section{Measuring Transformation}

For the purpose of measuring teacher transformation, many belief and attitudinal surveys are available that have been tested and standardized (Eccles \& Wigfield, 2002; Pajares, 1996). These are helpful for providing insight into the self-perceptions of the teacher and his/her transition. In addition, it is helpful to consider the actual observable practice in the classroom. Numerous observational protocols (i.e., Inside the Classroom, RTOP, EQUIP) are available to measure various components of instructional practice (Horizon Research, 2002; Marshall, Smart, \& Horton, 2010; Sawada et al., 2000). Common among these protocols is a focus on four key constructs associated with the facilitation of student learning: 1) instruction; 2) curriculum; 3) discourse; and 4) assessment.

Instruction. Uniting constructivist learning theory with inquiry-based instruction achieves learning that builds on prior knowledge, addresses student preconceptions, and engages students deeply in process and content (Abell, 2007; Bransford, Brown, \& Cocking, 2000; Bybee et al., 2006; Mortimer \& Scott, 2000, 2003).

Curriculum. Instructional effectiveness is limited by the quality of the curriculum. Critical curriculum components include depth of content studied, centrality of the learner in instruction, role of standards, and role of student in recording and organizing information and (Luft, Bell, \& Gess-Newsome, 2008; Marzano, Pickering, \& Pollock, 2001, 1996; Schmidt, McNight, \& Raizen, 2002; Wiggins \& McTighe, 2005).

Discourse. Some key components of discourse in science classrooms include the level and complexity of questions, the environment created for questioning, and the pattern of teacher-student and student-student communication (Ball \& Cohen, 1999; Kelly, 2007; Moje, 1995; Morge, 2005; Van Zee, Iwasyk, Kurose, Simpson, \& Wild, 2001). Teachers' questioning strategies are central to inquiry instruction yet often differ from questioning in more traditional contexts (Duit \& Treagust, 1998). Inquiry-based questioning seeks to elicit student thought processes, encourages students to elaborate on their ideas, adjusts based on student responses in an effort to engage students in higher-order thinking, and tends to be more open where teacher responses are neutral rather than evaluative (Baird \& Northfield, 1992; Chin, 2007).

Assessment. Properly integrating formative assessment in instruction is central to effective science teaching practice (Marshall, Horton, \& Smart, 2009; Marzano, 2006). Further, effective instruction incorporates assessment that draws upon student prior knowledge, develops solid conceptual development, involves student reflection, and provides varied and appropriate assessments (Bell \& Cowie, 2001; Black \& Wiliam, 1998; Bransford et al., 2000; Driver, Squires, Rushworth, \& WoodRobinson, 1994; Stiggins, 2005; White \& Frederiksen, 1998; Wiggins \& McTighe, 2005).

\section{Problem/Purpose Statement}

This case study examines how sustained involvement in a PD institute assists teachers as they transform to greater quantity and quality of inquiry-based instruction. We sought to describe a spectrum of teachers' responses at various points during the PD intervention. Specifically, we examined their belief structures and classroom practices associated with inquiry-based instruction as transformation progressed.

\section{Method}

\section{Context}

Participants in the present study were part of a year-long PD intervention with the goal of increasing the quantity and quality of inquiry-based instruction in secondary science classrooms. An initial two-week summer session focused on immersing teachers in inquiry learning experiences, introducing the $4 \mathrm{E} \times 2$ Instructional Model for planning inquiry-based instruction (Marshall, Horton, \& Smart, 2009), and supporting the work of teacher-teams in developing inquiry exemplar lessons. Follow-up included four days during the academic year to provide continuing support, feedback, and guidance regarding the development, refinement, and implementation of inquiry-based instruction. Additionally, program facilitators made visits to participants' classrooms several times during each semester in 
order to provide personalized support for implementing exemplar lessons and to give regular feedback regarding implementation of inquiry lessons. This sustained PD model allowed facilitators to provide on-going, individualized support for teachers as they transitioned to more inquiry-based instructional practices.

\section{Instructional Model}

The $4 \mathrm{E} \times 2$ Instructional Model (Marshall, Horton, \& Smart, 2009), which forms the curricular foundation for the PD intervention, builds upon the 5E Instructional Model (Bybee et al., 2006) and other similar inquiry models (Atkin \& Karplus, 1962; Eisenkraft, 2003; Karplus, 1977). All of these models including the original Learning Cycle (Atkin \& Karplus, 1962) from which most have been derived have at the core a belief that the learner needs to be perturbed so that the mind becomes engaged duirng learning - a Piagetian notion or constructivist approach. The 4E $\times 2$ Model incorporates three critical learning constructs: 1) inquiry instruction (NRC, 2000); 2) formative assessment (Black \& Wiliam, 1998); and 3) teacher reflection (2006). The $4 \mathrm{E} \times 2$ Model integrates these constructs into a single model to guide transformation of practice and improve student learning.

The following sequence is foundational to the $4 \mathrm{E} \times 2$ Model: Engage, Explore, Explain, and Extend. Specifically, Engage incorporates some or all of the following in the instructional sequence: activate prior knowledge, probe for misconceptions, provide motivation/interest/relevance, and/or develop scientific questions. During Explore, instruction is focused on getting students to predict, design, test, collect, and/or reason. Explain follows after student exploration, and the teacher helps students resolve misconceptions, tie key concepts to ideas explored, and has students communicated ideas through various means. In the process, students interpret and analyze data, provide evidence, communicate ideas, provide alternative explanations, and justify conclusions. During the Extend portion of instruction, students are provided opportunities to elaborate thinking, transfer learning to novel situations, and generalize to other settings. While the Model is dynamic and should adjust to the concept(s) being taught, the critical portion of the Model requires that students be provided an opportunity to Explore ideas, data, or concepts before a formal Explanation occurs. Unlike the $5 \mathrm{E}$ Model that places Evaluate at the end of the instructional sequence, the $4 \mathrm{E} \times 2$ Model explicitly embeds assessment within each phase of the lesson. Although assessment may be part of the 5E Model, it is not explicit in the model and left for teachers to interpret as to where and when it should occur. In addition, teacher reflection is also integrated into each phase of the lesson, encouraging teachers to make intentional decisions regarding assessment throughout a lesson.

During the summer training and academic year follow-up, guidance is given in how to move from what initially may seem as prescriptive steps to follow ( $4 \mathrm{E} \times 2$ Model) to a new way of thinking. For instance, teachers begin to grapple with how to move from Explain-Explore progression in learning to Explore-Explain. Further, teachers learn to become more of a facilitator, which includes beginning, when possible, with student explanations instead of teacher presentation/lecture. Finally, during the two weeks of summer interaction, one day was dedicated to experiencing, discussing, and troubleshooting each "E" in the Model.

\section{Participants}

A purposeful selection (Creswell, 2008) of three high school physical science teachers (Table 1) was drawn from the eighteen teachers taking part in the year-long PD program. Selection was based on their Electronic Quality of Inquiry Protocol (EQUIP) scores (Marshall, Horton, Smart, \& Llewellyn, 2008) in order to represent an array of levels (high, medium, and low) of implementation of inquiry as the school year began. For example, Anne (high) was selected because her high initial scores on EQUIP indicated a smooth transformation to inquiry-based instruction. Conversely, Carla (low) was selected because her EQUIP scores show a teacher who was experiencing more difficulty in transforming her instructional practices. These observations were conducted at the beginning of the school year, immediately following the summer portion of the PD intervention.

\section{EQUIP Details}

EQUIP is a highly reliable and valid instrument that is used to measure the quality of inquiry that occurs in a given class period. The development and standardization of the instrument have been previously addressed in detail this includes inter-rater reliability (Marshall et al., 2010; Marshall, Smart, Lotter, \& Sirbu, 2011). Two reviewers (a professor in science education and a doctoral student) scored the EQUIP and collected the field notes. A weekly meeting was held to discuss the data and findings. Further, numerous paired observations were held throughout the academic year to insure that inter-rater agreement remained consistently high. EQUIP measures 19 indicators that are divided among four major learning constructs: instruction, discourse, curriculum, and assessment.

\section{Data Collection and Analysis}

This multiple-case design (Yin, 2003) focused on the individual responses of three distinct and unique perspectives, especially in the area of inquiry beliefs and transference of PD experiences to instructional practice. True to Yin's (2003) multiple-case, embedded design, used in this study, the with-in case analysis (analysis of individual cases) preceded the cross-case analysis (comparison of multiple cases) (Creswell, 2008; Merriam, 1998; Yin, 2003).

Table 1.

Demographic details associated with the three teachers studied.

\begin{tabular}{ccccc}
\hline Participants $^{1}$ & Years teaching & Highest degree & Race & Teaching schedule \\
\hline Anne & 2 & Bachelor's & Caucasian & 90 minute $4 \times 4$ block \\
Beth & 12 & Bachelor's & Caucasian & 50 minute \\
Carla & 15 & Master's & African American & 90 minute AB block \\
\hline
\end{tabular}

Note: ${ }^{1}$ Pseudonyms used. 
Data collection involved the following sources: 1) pre and post survey data; 2) classroom observations using an inquiry observational protocol; 3) field notes; 4) teacher interviews; and 5) transcripts of classroom recordings. Using multiple data sources helped ensure triangulation (Denzin \& Lincoln, 1994) and construct validity within the case study design (Yin, 2003).

All data were checked for consistency. Pre and post survey data and inquiry protocol ratings were triangulated, crosschecked with the other qualitative data sources. Based on this analysis, the following embedded units of analysis (Yin, 2003) became the foci for this study: 1) teachers' transformation of belief structures regarding inquiry resulting from the PD experience and 2) teachers' transformation of classroom practices resulting from the PD experience.

\section{Belief Structures}

Teachers' beliefs about and use of inquiry-based instruction were determined via a pre and post survey that measured: 1 ) self-efficacy (alpha $=.87$ for four-item sub-scale); 2) perceived support (alpha $=.87$ for two-item sub-scale); and 3) value of inquiry as an instructional strategy (Marshall, Horton, Igo, \& Switzer, 2009).

The self-efficacy scale was composed of items such as, During inquiry, I can manage my students' behavior, and I can effectively lead students in inquiry. The support scale items included the following two statements: My school's administration is supportive of inquiry instruction, and The faculty at my school is supportive of inquiry instruction. After each statement, participants selected from a Likert-type scale (1 = completely disagree, 2 = strongly disagree, 3 = somewhat disagree, $4=$ somewhat agree, $5=$ strongly agree, and $6=\mathrm{com}$ pletely agree). Finally, value was determined using the following two items: 1) Which value best represents the percentage of instructional time your students are engaged in inquiry during a typical lesson? and 2) Ideally, what percentage of instructional time should be devoted to inquiry?

Teacher interviews were conducted in order to examine teachers' conceptions and beliefs about inquiry throughout the year-long PD. Interviews were transcribed, coded, and then analyzed. Open coding was used to identify initial concepts. Then, similar concepts were grouped to create categories related to teachers' shifting belief structures. Multiple data sources (interviews and survey results) allowed for triangulation of teachers' inquiry beliefs data.

\section{Classroom Practices}

Teachers' inquiry belief structures represented contextual factors that are mediating variables in transformation of actual classroom practice. This transfer of PD experiences to teaching practice was the principal focus of the case study. How and to what degree inquiry-based instruction was implemented was determined by using an observational protocol, field notes, and a transcription of the audio taped observation.

EQUIP was used to assess the following four constructs: 1) instruction; 2) discourse; 3) assessment; and 4) curriculum (Marshall et al., 2008; Marshall et al., 2010). The current version of EQUIP contains the same constructs and indicators as the one used in this study. The difference being that we have switched from the 5 -point Likert scale $(1=$ not at all to $5=$ to a great extent) used in this study to a 4-point descriptive rubric. In addition to the EQUIP ratings and field notes, audio re- cordings of classroom sessions were transcribed to allow in-depth analysis of instructional interactions. All qualitative data were analyzed using the constant comparative method (Strauss \& Corbin, 1998). Collectively, the protocol, field notes, and transcripts allowed for triangulation of multiple data sources to better understand how teachers implemented and facilitated inquiry instruction. We begin the data analysis exploring each of the three within cases.

\section{Within-Case Analysis}

\section{Case One: Anne}

Belief Structures. Anne reflected on her beliefs, specifically the challenges, central to her emerging inquiry practice: "Physics came easy to me... everything I did was inquiry, and then I got to chemistry and I was stuck again. I didn't know what to do.” Anne's challenges of bridging content domains were further complicated by her feeling that she often lacked a solid engage component and was thus not able to adequately lead the development of scientific questions. Anne further discussed the challenge of helping students transfer new understandings through inquiry investigations to mandated "test" items: "Students had a difficult time transferring their inquiry learning... to a more concrete form on a written test.” For her, any solution must involve providing ways to make the abstract more concrete.

Anne's pre and post survey responses remained consistently high for both the typical percentage time devoted to inquiry-based instruction (40\%) and the ideal percentage of time that should be spent on inquiry instruction (80\%). Furthermore, her motivation to use inquiry instruction remained high despite a drop in perceived support for inquiry. Table 2 details all the above scores relative to the other case study participants and the district teachers $(\mathrm{N}=71)$.

Classroom Practices. Anne's primary growth in inquiry practice occurred in the areas of discourse (questioning strategies and instructional interactions) and instruction (redefinition of her role as a teacher) observed from the observational protocol, field notes, and transcripts.

Using the observational protocol as a framework, Anne's questioning strategies consistently received 4's and 5's (on a scale where $1=$ not at all and $5=$ to a great extent) in the following areas: "The teacher asked questions that foster conceptual understanding," and "The teacher asked questions that stimulated higher level thinking." As the school year progressed, Anne transitioned from closed-ended questioning strategies to ones that encouraged higher levels of cognitive engagement. Anne scaffolded questions to move students to more thoughtprovoking responses as seen in the following activity on chemical bonding:

Teacher: Look at the two elements... How might they bond? Do you know anything that would make you choose one element over another to bond with?

Student: I think there is something about where they are on the periodic chart.

T: What do you know about elements on the periodic chart? How are they organized?

$\mathrm{S}$ : Some are grouped together because they have some of the same properties. Right?

T: What kind of properties are we talking about here?

S: Like, the number of electrons? (transcript, ob4)

Through her questioning, Anne encouraged students to pro- 
vide explanations and justifications for their conjectures and hypotheses. Anne also restated student ideas and "used follow-up questions to provide opportunities to clarify and expand on student thinking” (field notes, ob3).

Furthermore, Anne discussed how she practiced these new questioning strategies by using effective questioning to guide student understanding; "Well, it helps me to know if they truly understand what they're talking about or if they're just using words they've heard before.” For Anne, effective questioning allowed her to "push students to really think..., not just repeat what they think I want to hear.” Follow-up questioning allowed Anne to help students elaborate publicly on their conceptions in order to help struggling students improve their understandings.

Regarding instructional interactions, Anne averaged 5's on protocol items involving creating a climate of respect for students' ideas and building positive relationships between teacher and students. Anne demonstrated respect and value of student conjectures thus increasing the intellectual rigor. Throughout instruction, Anne "encouraged students to listen to each other and discouraged negative comments from other students during class discussions" (field notes, ob2) and demonstrated her belief that her students are capable of exploring scientific content in a challenging manner. The following discussion on speed and velocity illustrates this point:

S: I thought that speed and velocity were the same thing.

T: Well, tell me why you thought that?

S: When you're dealing with velocity, ... you are talking about how fast something is going, and when you're talking about speed, it's the same thing. So velocity would be faster.

$\mathrm{T}$ : Remember that velocity has direction. With speed, it doesn't matter which way things are moving. Does that make sense?

S: No, not really.

T: Let's talk about this more while the class begins the next activity (trans, ob2).

Anne's interactions with students were consistent, stable, respectful, and fair, contributing to an overall classroom environment where students were expected to evaluate scientific conjectures and to respect the ideas of others. This respect translated into "student respect for each other and a willingness to share openly with peers without fear of being wrong" (field notes, ob1).

Finally, protocol ratings increased from 2's in the Fall to 4's in the Spring on facilitating "using evidence to formulate conclusions," "justifying conclusions," and "extending learning to new contexts." She more frequently facilitated student explorations instead of disseminating information via lecture. The following field notes show Anne's transformation in her role:

Fall: Anne writes the formula for velocity on the board and has students copy the formula and work sample problems in their notebooks. While students are working the problems, Anne walks around helping students who are having difficulty with computations, often pointing out their errors in calculating velocity (ob2).

Spring: Students are given elements and hole-punch paper circles, and students must arrange the Lewis Dot Structures for each compound. Walking around, Anne questions them about their work and provides some guidance but allows students to grapple with the activity on their own and through interaction with other students (ob5).

These examples show Anne's transformation from "keeper of knowledge” to instructional guide. By year's end, Anne guided students to develop their own conceptual understandings and helped them to explore scientific questions instead of memorizing science content.

Throughout the year, Anne reflected on her evolving role as teacher. Before, Anne "presented formulas or scientific ideas and then allowed students to do activities relating to the information I gave them.” Thus, she typically explained ideas before allowing students to explore. Aligned with the $4 \mathrm{E} \times 2$ Model, Anne now often allows students to explore scientific ideas before she explains the underlying concepts. Anne stated, "[The students] ask scientific questions, and the only thing I really do is to find a way to construct the classroom set-up in a way that allows them to investigate these questions.” After students explore, the explain phase allows students to discuss findings and create meaning to support student understanding.

Anne's transformations in her inquiry beliefs and related classroom practices demonstrate the transition to inquiry-based instruction. She increased her knowledge about inquiry during the year-long PD institute and has subsequently improved implementation of inquiry instruction. This growth has motivated Anne to "continue developing inquiry activities, especially in the area of chemistry." Obstacles are frequently negated by the value she places on inquiry as an effective instructional method: "It just is a very logical way of going about things. You question, let them learn on their own, and then go back and expand on what they've learned."

\section{Case Two: Beth}

Belief Structures. Beth's perspective of inquiry-based instruction was concise both pre and post. Her pre-conception addressed two key issues: 1) what inquiry is - "cause student to think”, and 2) what inquiry is not- “just filling in worksheets.” Thus, she emphasized critical thinking associated with inquiry instead of supporting procedural, completion type activities associated with non-inquiry. Beth's post conception of inquiry-based instruction focused on two completely different aspects: 1) the importance of prior knowledge and 2) learning by mistakes. This begins to demonstrate her unstable, almost amorphous view of inquiry.

Beth's conception of inquiry-based instruction, "Using past knowledge to learn something new," lacks the specificity seen in the NSES definition. Other than "examining... what is already known," cited by NSES there is little correlation between the two views. Her response shows an overly simplistic view of inquiry, letting students "make mistakes" and causing them to "think." Missing was any mention that science uses a systematic approach to inquire about problems.

Beth's survey results indicated a relative contentment in her instructional practice regarding inquiry-based instructional practice. Her pre percentage of time spent on inquiry matched her ideal percentage of time that should be spent on inquiry (40\%). A drop in her post typical percentage of time being spent on inquiry reported might be attributed to a better understanding of her actual classroom practice that now aligns with the mean for science teachers previously surveyed (Table 2). Her motivational score was slightly higher than the district average and remained unchanged from the pre and post measure. Beth's perceived support was also higher than the district average and remained stable throughout the school year.

Some growth in understanding of inquiry practice was seen with Beth. Specifically, she realized that inquiry is more than 
Table 2.

Pre- and post-intervention scores for participants relative to district norm.

\begin{tabular}{ccccc}
\hline & Typical \% of inquiry & Ideal \% of inquiry & Mean for self-efficacy scale (4-24 possible) & Mean for support scale (2-12 possible) \\
\hline District $^{\mathrm{i}}$ & 28.5 (SD 15.4) & 44.8 (SD 20.4) & 18.8 (SD 2.58) & 9.3 (SD 1.56) \\
Anne & 40,40 & 80,80 & $18,18^{\mathrm{ii}}$ & $10,8^{\mathrm{ii}}$ \\
Beth & 40,20 & 40,40 & 19,19 & 10,10 \\
Carla & 20,40 & 40,60 & 19,24 & 11,9 \\
\hline
\end{tabular}

Note: ${ }^{i} \mathrm{~N}=71$ high school science teachers (sampled from entire district population); ${ }^{\text {ii }}$ Pre intervention, post intervention scores.

just hands-on activities for students; she realized the importance of using student prior knowledge to guide instruction; she noted that her understanding of inquiry has expanded to include a focus on "relating science content to real life and finding a way to make it meaningful to the students"; and, her understanding of her role as a teacher during inquiry had expanded. She realized the need to actively facilitate learning during inquiry instruction. She stated: "With inquiry, you have to lead it more and have to be in the middle of it and that leaves less time to finish paperwork and other work I have to do.”

Reflecting on her emerging inquiry pedagogy, Beth saw the need to default to a more teacher-centered approach when things became challenging: "When the school year started, I was trying to do more inquiry, but as the year went on I fell back on my old ways of teaching." Beth typified these "old ways of teaching” as giving notes, using worksheets, and giving activities from the textbook. She perceived a lack of curricular support for inquiry: "The supplements that you get for textbooks, it's all fill-in-the blank and worksheets. Everything you do with inquiry, you have to come up with on your own." However, she noted that exemplar lessons, designed by teams during the summer PD, were helpful in her transformation toward inquiry instruction. Additionally, Beth noticed her interactions with students evolved during the year. Beth noted, “They will come to me asking, 'Is this right?' I try to get them to ask the other people in their group. I also learned to have them rely on each other, not just on me."

During the year-long PD experience, Beth increased her understanding of inquiry and reflected on her emerging pedagogy in relation to inquiry-based instruction. She became aware of the challenges of implementing inquiry when peers are generally aligned with non-inquiry approaches. Beth also discovered that transitioning to inquiry is a process: "You start, but I know I've got so much more to learn. It's so easy to go back to what you know." She noted that students also experience a parallel transformation as they learn through inquiry-based instruction.

Coming from middle school, they are so used to having worksheets... reading straight from the book and answering questions... just memorizing. They've been spoon-fed the information, so once they get in here and it's not that way, they have to adjust.

Classroom Practices. Beth's instructional practices during the school year were distinguished by her use of formative assessment, attention to student prior knowledge, and reliance on non-inquiry based forms of instruction.

Beth scored mostly 4's throughout the year on formative assessment issues such as: "The teacher adjusted instruction based on students' level of understanding." On one occasion,
Beth "presented students with several chemical formulas to balance that included polyatomic ions" (field notes, ob1). As students worked, Beth recognized student confusion about the role of oxidation numbers in creating neutrally charged molecules. Instead of proceeding with instruction, Beth adjusted and reviewed oxidation numbers for the remainder of the period. In another class, Beth's use of questioning to check for student understanding showed students exploring classification of living things:

T: We've talked about animal life, plant life, parasites, and decomposers. Which one survives from a live host?

S: Well, I think it would be decomposers.

$\mathrm{T}$ : Why would you choose decomposers over the other choices?

S: Well, they eat dead things, right? So couldn't they also eat things that are alive?

From this questioning sequence, Beth realized that students did not have an accurate understanding of the distinction between parasites and decomposers. Instead of progressing to a new activity, she reviewed and clarified the differences between parasites and decomposers. Beth demonstrated a propensity for 'checking the status of her students' understanding of science concepts before moving on to new material” (field notes, ob1).

Beth averaged 4's on the protocol items that measured the degree that the teacher assessed and then used student prior knowledge during the lesson. She used pre-assessments and class discussions to check for prior knowledge. Before beginning a lab, Beth "led a class discussion of the major body systems of animals to see what information students already knew or had previously encountered" (field notes, ob3). This discussion helped Beth incorporate prior knowledge into her facilitation of the dissection lab. During the lab, Beth provided a variety of resources including anatomical diagrams and detailed descriptions to support students with varying degrees of prior knowledge regarding anatomy. In a post observation discussion, Beth added, "Finding out what students already know helps me to build on that and avoid just re-teaching things that students already understand.”

While Beth showed several solid characteristics of being able to facilitate inquiry-based instruction through her use of formative assessment and attention to student prior knowledge, she also tended to default to teacher-centered modes of instruction. On the observation protocol, Beth typically scored 2 or below on items relating to the following constructs: exploring scientific questions, student justification, use of scientific evidence, and extension of learning to new concepts. She earned many low scores based on of her use of many non-inquiry approaches such as lecture, her use of worksheets for practice, and her teaching content in isolation from process. Lessons often pro- 
gressed sequentially through presenting information or formulas, working examples as a class, and practicing independently (field notes, ob2 and 3).

\section{Case Three: Carla}

Belief Structures. Carla's summer conception of inquirybased instruction had two components: 1) teacher engagement-“teacher introduces a concept”, and 2) student exploration- "students will explore the concept". Her spring inquiry conception was greatly revised and began with a "studentdriven" focus where students are engaged before they explore a concept. Her final statement reemphasizes the student-centeredness, "Students are allowed to design their own experiments based on a problem or question which they want to investigate that came up in assessing prior knowledge and addressing misconceptions.” Perhaps the PD experience spurred by her prior desire to excel with National Board Teacher Certification was responsible for some of her new conceptions.

Carla's post conception of inquiry instruction from the survey clearly illustrated how to facilitate the process of an inquiry investigation. Students are "engaged" often by a "discrepant event" and then students are allowed to "explore" the concepts collaboratively. Further, "students are allowed to design their own experiments based on a problem or question." This vision supports how inquiry defined by NSES is achieved. Carla's articulation aligns with multiple definitions of inquiry (Donovan \& Bransford, 2005; Llewellyn, 2005; NRC, 1996; NRC, 2000).

Carla grew in her pre to post view of the percentage of time spent on inquiry from $20 \%$ to $40 \%$. Similarly, her pre and post reporting of the ideal percentage of time that should be spent on inquiry increased from $40 \%$ to $60 \%$. The motivational composite for Carla showed a pre score of 19 and a post score of 24 . This post view is more than one full SD above the district average (see Table 2). This optimism is present despite a lower perceived support for inquiry instruction (pre score of 11 and post score of 9). It is notable to see increased beliefs regarding and motivation for inquiry instruction despite a decreased level of perceived support for inquiry instruction.

During the PD experience, Carla developed a new understanding of inquiry. "I thought that science inquiry was just having students do hands-on things. But then I could start seeing what it was that I was doing wrong” (interview). Then Carla elaborated on the process of inquiry that must distinguish between student activity and student engagement, “... they [students] have to be actively involved. I just present the thought, and they have to decide how to approach it. They have to put ownership into it.” This belief in student ownership was seen as Carla gave students opportunities to explore scientific questions by designing and conducting their own experiments.

Carla also reflected on her emerging pedagogy and described her teaching practices prior to the PD as “traditional.” By year's end, she mentioned still relying on many traditional, non-inquiry methods but placed a priority on integrating inquiry slowly into practice. She described her transformation as "a process" adding, "I still do some traditional teaching. But this [inquiry] just ... adds a new dimension to what I'm doing." Carla also noted that her planning changed as she implemented more inquiry. Previous planning involved developing notes and practice problems, but now Carla engages more intentionally with content when planning inquiry experiences. She describes the planning process, "I had to do more research to try to an- ticipate their questions... It took more time, but I think it was worth it."

Classroom Practices. Carla's instructional practices during the year were distinguished by her questioning during inquiry and non-inquiry instruction, engaging students in designing inquiry-investigations, and displaying an "all-or-nothing” approach to inquiry instruction.

Carla's instructional practices, specifically her questioning techniques, modeled the two extremes by either showing strong inquiry instruction or none at all. When using a non-inquiry approach, Carla's questioning became single response, right-orwrong questions or statements such as: 1) "What's the atomic mass for K (potassium)?" 2) "The atomic mass is the molar mass in grams. So the unit here is going to be in grams." (trans, ob3)? When Carla's instruction was inquiry-based, her discourse became more open-ended, placing less emphasis on the correctness of the answer and more focused on the process: 1 ) "Is there something in the gum that helps you blow bubbles?" 2) "Choose an ingredient and describe how you would find the percent composition in the gum” (trans, ob2).

During inquiry-based instruction, this use of questioning allowed Carla to "help her students think beyond the obvious answers and to explore topics on a deeper level" (field notes, ob2). Even though the discourse pattern is more open-ended only statement two was an attempt to scaffold understanding of specific content knowledge. When students were given the opportunity to respond to follow-up questions, they were more likely to expand on their thinking and address science concepts at a higher cognitive level. In contrast, student responses to the closed questioning "were evaluated simply against a standard of 'right or wrong." Carla reflected on her use of questioning strategies to engage students with scientific concepts: "If I ask a student a question now, I say, What do you think about it? instead of me just answering the question or directly giving them the information. I solicit input instead of me being the one on stage."

During her instructional practice, Carla also engaged her students in conceptualizing and carrying out an investigation to explore a scientific question. During a lesson on percent composition, Carla's students developed a plan for studying the scientific question, the percent composition of sugar in bubble gum. During this two-day investigation, Carla allowed students to grapple with the challenges they encountered in carrying out the experiment. Further, the following illustrates how she scaffolded their development: 1) "Think about the materials you have. Could you use any of these to help you?" 2) "Why would you want to weigh it? What would that tell you?” (trans, ob2). In just a few minutes, this group had figured out that they needed to weigh the gum, chew it to remove the sugar, and then weigh it again in order to perform the computations for percent composition. By acting as a guide, Carla engaged her students in active inquiry that challenged them to "explore science concepts instead of just memorizing facts” (field notes, ob2).

Carla continued to exhibit an "all-or-nothing" approach to inquiry-based instruction throughout the school year. Considerable differences were noted between Carla's inquiry and non-inquiry teaching on the section of the observation protocol that addressed concepts such as student engagement with scientific questions, justification and communication of ideas, and transfer of concepts to other contexts. When Carla adopted an inquiry-based approach, her students were engaged, explored scientific questions, provided evidence to support and justify 
their conclusions (thus earning her 4's and 5's on relevant protocol items). Further, peer-peer and teacher-student interactions increased during these inquiry lessons, and greater flexibility encouraged students to explore open-ended scientific questions. In contrast, during a non-inquiry lesson, students "copied notes, worked examples from the board, and reviewed their answers as a class" (field notes, ob3). Additionally, "student interactions were almost non-existent, as student verbal responses were limited to single responses to teacher-initiated closed questions” (field notes, ob3). Thus, scores dropped to mostly 2's during non-inquiry approaches.

Carla's PD involvement contributed to her growth and implementation regarding inquiry instruction. Though daunting to some teachers, Carla maintained a realistic vision for transforming instruction to greater quantity and quality of inquirybased teaching and learning; "I know I'm still doing some things wrong, but it's a process." Carla recognized for her that the transformation is and should be a gradual one. After 15 years of teaching science, primarily through "traditional" methods, Carla indicated her intention to continue her growth regarding inquiry instructional practices. Carla stated, "When I first went into the class [PD], I didn't think it would be a huge deal, but it ended up being a huge thing. It was a big thing personally."

\section{Cross-Case Analysis/Discussion}

Considerable differences in beliefs and practices were expected among the participants based on the selection method.
Tables 3 and $\mathbf{4}$ respectively provide a condensed view of the belief structures and the classroom practice of each of the three teachers featured in this collective case study. In viewing the tables, the data indicate that Anne is thriving in terms of inquiry practice; Beth now seems stuck but showed some evidence of growth; and Carla, who was previously stuck, is now growing dramatically.

With years of counter experience and with a desire to excel on the inquiry portion of National Board Certification, Carla experienced an awakening to inquiry and what it could mean for her students' learning. This "learning year" for Carla provided opportunities to practice and reflect on this new strategy. During the year, Carla's conception of inquiry shifted to align with the NSES definition, her motivation for implementing inquiry increased, and her ideal percentage of time that should be devoted inquiry increased. This growth occurred despite a decreased perception of support from peers and administration. Now possessing a solid understanding of inquiry-based instruction, Carla needs additional support to spur these conceptions into practice.

Only Anne and Carla seemed developmentally ready to transition to a more inquiry-focused culture. Anne's multiple previous exposures to inquiry-based instruction assisted her to transform her practice more quickly. Carla began her transformation but will need continued support over the next few years before this will become an integral part of her instructional practice. Although receptive to the idea of inquiry instruction, Beth will need something more significant than this PD experience before inquiry instruction becomes a regular part of

Table 3.

Summary of belief structures for cross-case.

\begin{tabular}{|c|c|c|c|}
\hline Category & Anne & Beth & Carla \\
\hline Conceptions of inquiry & $\begin{array}{l}\text { Solid understanding: consistent, } \\
\text { well-aligned with NSES definition. }\end{array}$ & $\begin{array}{l}\text { Surface understanding: pre- and post } \\
\text { responses lacked any specificity. }\end{array}$ & $\begin{array}{l}\text { Developing understanding: solid } \\
\text { growth seen toward deeper } \\
\text { understanding, which included } \\
\text { understanding of Nature of Science. }\end{array}$ \\
\hline Beliefs in inquiry practice & $\begin{array}{l}\text { Maintained high belief: motivation } \\
\text { and implementation remained high } \\
\text { despite lower perceived administrative } \\
\text { support. }\end{array}$ & $\begin{array}{l}\text { Decreased or stable belief: reported } \\
\text { amount of inquiry practice decreased, } \\
\text { but practice remained constant suggesting } \\
\text { better understanding not decreased amount. }\end{array}$ & $\begin{array}{l}\text { Increased belief: } \\
\text { both actual and ideal amount } \\
\text { of inquiry increased, which } \\
\text { was supported by observations. }\end{array}$ \\
\hline
\end{tabular}

Table 4.

Summary of classroom practices for cross-case.

\begin{tabular}{|c|c|c|c|}
\hline Category & Anne & Beth & Carla \\
\hline $\begin{array}{l}\text { Role } \\
\text { of teacher }\end{array}$ & $\begin{array}{l}\text { Facilitator of learning: I need to truly } \\
\text { understand what they're talking about } \\
\text { and to see if they're just using words } \\
\text { they've heard before without any } \\
\text { true understanding of the science content. }\end{array}$ & $\begin{array}{l}\text { Shifting role from giver of knowledge } \\
\text { to facilitator: inquiry teaching has helped } \\
\text { me not to just give students all the } \\
\text { answers. }\end{array}$ & $\begin{array}{l}\text { Developing facilitator: If I ask a student a } \\
\text { question now, I want to say, "What do you } \\
\text { think about it?" Instead of me just expecting } \\
\text { an answer or answering the question or } \\
\text { giving them too much information. }\end{array}$ \\
\hline $\begin{array}{l}\text { Questioning } \\
\text { strategies }\end{array}$ & $\begin{array}{l}\text { Consistently engaging and challenging: } \\
\text { Utilized questioning to scaffold student } \\
\text { learning, assess student knowledge, and } \\
\text { challenge students to interact with } \\
\text { science content at higher cognitive levels. }\end{array}$ & $\begin{array}{l}\text { Old habits hard to break: Defaulted } \\
\text { primarily to closed, lower-level } \\
\text { questioning strategies during inquiry } \\
\text { investigations. }\end{array}$ & $\begin{array}{l}\text { All-or-none: adopted an "all-or-nothing” } \\
\text { approach to inquiry and her questioning } \\
\text { patterns demonstrated that idea. }\end{array}$ \\
\hline $\begin{array}{l}\text { Role of } \\
\text { students }\end{array}$ & $\begin{array}{l}\text { Students must think and justify responses: } \\
\text { Students' desires to always be right made } \\
\text { it challenging to get them to "think on } \\
\text { their own" during inquiry learning. }\end{array}$ & $\begin{array}{l}\text { Students need to become independent: } \\
\text { She felt student independence is necessary } \\
\text { for inquiry-based instruction to be effective. }\end{array}$ & $\begin{array}{l}\text { Students must engage collaboratively: } \\
\text { She saw students began thinking and } \\
\text { actively seeking information from } \\
\text { their peers during lab explorations. }\end{array}$ \\
\hline $\begin{array}{l}\text { Content } \\
\text { background }\end{array}$ & \multicolumn{3}{|c|}{$\begin{array}{l}\text { Inquiry best in content forte': all three clearly acknowledged, agreed, and displayed better inquiry in content area where most teaching } \\
\text { experience and content knowledge exists. Inquiry success not limited to specific domain of science. Anne was best in physics; Beth in } \\
\text { biology; and Carla in chemistry. }\end{array}$} \\
\hline
\end{tabular}


instruction. Part of Beth's difficulty is that she possesses an inaccurate conception of inquiry according to any of the available definitions. Since this intervention, the presentation of the $4 \mathrm{E} \times 2$ Model during the summer has become more interactive with numerous attempts made to reference specific lessons that were taught. The goal is to get teachers like Beth who seem "stuck" in their current instructional approaches to see that it is possible to begin to change instruction so as to improve student achievement and critical thinking. Specifically, more emphasis is given to discussing, role-playing, and reflecting how to move Exploration of ideas ahead of Explanation. The intention is not to make the $4 \mathrm{E} \times 2$ Model a prescribed path to follow for inquiry; rather, the Model provides a means for conversation and common language.

\section{Conclusion and Implications}

The challenge of raising the quality of inquiry in science classrooms has been at the forefront of discussions in science education since before the NSES was written. Teachers are clearly aware of the need to teach using inquiry-based methods. However, they are generally very uncertain how to bridge from awareness to competent practice. The uncertainty stems from many things. Specifically, there is discrepancy in teachers' conceptions of inquiry (Anderson, 2002), and inquiry's complex, multifaceted nature can make inquiry a challenging method to implement (Vanosdall, et al., 2007; Windschitl, 2008).

So, how successful are sustained PD experiences in transforming teacher practice to inquiry-based instruction? For the highlighted PD experience, the answer seems to be one of partial success. All three teachers came with an awareness of inquiry-based instruction; all increased their understanding; all translated new knowledge regarding inquiry instruction into practice; all practiced these new strategies; all reflected on emerging pedagogy; but only Anne created a classroom culture of inquiry. On the surface, it may seem that all three teachers were nearly equal in their proficiency to implement inquiry. However, the degree of each teacher's growth and proficiency relating to each of the above stages varied considerably. These variances were largely evidenced through the observation protocol (Marshall et al., 2008) and the final interview with each teacher.

Perhaps growth was influenced by some or all of the following factors: beliefs toward inquiry-based instruction, motivation to implement inquiry, support received to encourage its implementation, knowledge in the subject being taught, and exposure and practice using the method. Anne possessed all of these and was the only one to demonstrate a consistent classroom culture of inquiry.

When teachers teach science as inquiry, they create a sustainable instructional method that simultaneously fuses learning content and process. Since teachers are typically not recalcitrant to inquiry instruction-29\% of their time is self-reported doing so with an ideal of $45 \%$ (Marshall, Horton, Igo et al., 2009), the question becomes how to scaffold development so that the ideal is realized. A critical key seems to be helping teachers to become more intentional in moving from mere activities that just address a topic to more meaningful investigations that unite the content with inquiry in ways that develop critical thinking and conceptual understanding.

Although all teachers do not under go the same transformation in their teaching, our PD experience showed that teachers had a difficult time transitioning from the lessons and units developed during the summer and implemented during the year to the remainder of their instructional practice. This challenge has largely been resolved in subsequent PD experiences by targeting teacher cohorts from a few schools instead of teachers over several districts; this additional support network provides a collaborative means to create a school inquiry culture in feasible and realistic ways. Further, a new dynamic web-interface (Marshall, Horton, \& Smart, 2009) allows teachers to develop, implement, and share content-rich inquiry lessons. This interface has not only provided support for the teachers, but it also extends the social environment of the PD. These modifications now provide additional resources and support for teachers as they develop and refine inquiry-based instruction in their science classrooms. Since all teachers begin from a unique baseline in their teaching proficiency in terms of inquiry-based instruction, the hope is that the online resources will provide an array of experiences so that individual needs can be addressed. For instance, some may just need to view video samples to improve their questioning skills. While others may need to see how a lesson looks that flips the traditional paradigm so that Explore now precedes Explain.

Finally, if we hope, as leaders of PD experiences, to assist teachers in transforming toward greater quantity and quality of inquiry-based practices, then it needs to be a sustained experience that provides sufficient support in the areas of greatest need (Supovitz \& Turner, 2000). Based on this study, the sustained experiences that appear to support transformation of practice include differentiating to accommodate varied prior knowledge, unique understandings, and different beliefs of the participants. This can be partially achieved by providing group interactions that provide sufficient time for reflective practice to bridge the current PD experience with the individual classroom needs. Also, by providing individual classroom support during the academic year, teachers can be supported enough to encourage transformation of practice. Although the three cases provide a nice broad spectrum of teachers that are seen across the country, it is impossible for these teachers to represent all teachers at all grade levels. However, what can be generalized is the importance that the factors involved in transformation play in teacher success that include, among other things: significant time dedicated to support transformation, support for inquiry from administration, ability to engage students in effective discourse and questioning, and their role as a teacher. Certainly other factors contribute to this to success and transformation that have not been mentioned or even studied in this manuscript.

\section{REFERENCES}

Abd-El-Khalick, F., \& BouJaoude, S. (1997). An exploratory study of the knowledge base for science teaching. Journal of Research in Science Teaching, 34, 673-699.

doi:10.1002/(SICI)1098-2736(199709)34:7<673::AID-TEA2>3.0.C O;2-J

Abell, S. K. (2007). Research on science teacher knowledge. In S. K. Abell, \& N. G. Lederman (Eds.), Handbook of research on science education. Mahwah, NJ: Lawrence Erlbaum Associates.

Anderson, R. D. (2002). Reforming science teaching: What research says about inquiry. Journal of Science Teacher Education, 13, 1-12. doi:10.1023/A:1015171124982

Atkin, J., \& Karplus, R. (1962). Discovery of invention? Science Teacher, 29, 45. 
Baird, J. R., \& Northfield, J. R. (1992). Learning from the PEEL experience. Melbourne: Monash University Printing.

Ball, D. L., \& Cohen, D. K. (1999). Developing practice, developing practitioners: Toward a practice-based theory of professional education. In L. Darling-Hammond, \& G. Skyes (Eds.), Teaching as a learning profession: Handbook of policy and practice. San Francisco: Jossey-Bass.

Bell, B., \& Cowie, B. (2001). The characteristics of formative assessment in science education. Science Education, 85, 536-553. doi:10.1002/sce.1022

Black, P., \& Wiliam, D. (1998). Assessment and classroom learning. Assessment in Education, 5, 7-74. doi:10.1080/0969595980050102

Bransford, J. D., Brown, A. L., \& Cocking, R. R. (2000). How people learn: Brain, mind, experience, and school (expanded ed.). Washington DC: National Academies Press.

Briscoe, C. (1991). The dynamic interactions of beliefs, role metaphors, and teaching practices: A case study of teacher change. Science Education, 75, 185-199. doi:10.1002/sce.3730750204

Bybee, R. W., Taylor, J. A., Gardner, A., Scotter, P. V., Powell, J. C., Westbrook, A., \& Landes, N. (2006). The BSCS 5E instructional model: Origins, effectiveness, and applications (p. 49). Colorado: Colorado Springs.

Chiappetta, E. L., \& Koballa, T. R. J. (2006). Science instruction in the middle and secondary schools: Developing fundamental knowledge and skills for teaching (6th ed.). Upper Saddle River, NJ: Pearson Perrill Prentice Hall.

Chin, C. (2007). Teacher questioning in science classrooms: Approaches that stimulate productive thinking. Journal of Research in Science Teaching, 44, 815-843. doi:10.1002/tea.20171

Creswell, J. W. (2008). Educational research: Planning, conducting, and evaluating quantitative and qualitative research (3rd ed.). Upper Saddle River, NJ: Pearson Education, Inc.

Denzin, N. K., \& Lincoln, Y. S. (1994). Handbook of qualitative research. Thousand Oaks, CA: SAGE.

Donovan, M. S., \& Bransford, J. D. (2005). How students learn-Science in the classroom. Washington DC: National Academy Press.

Driver, R., Squires, A., Rushworth, P., \& Wood-Robinson, V. (1994). Making sense of secondary science: Research into children's ideas. London: Taylor \& Francis Ltd.

Duit, R., \& Treagust, D. (1998). Learning in science: From behaviorism towards social constructivism and beyond. In B. J. Fraser, \& K. G. Tobin (Eds.), International handbook of science education. Dordrecht: Kluwer Academic Publishers. doi:10.1007/978-94-011-4940-2 1

Eccles, J. S., \& Wigfield, A. (2002). Motivational beliefs, values, and goals. Annual Review of Psychology, 53, 109-132. doi:10.1146/annurev.psych.53.100901.135153

Eisenkraft, A. (2003). Expanding the 5E model: A proposed 7E model emphasizes "transfer of learning" and the importance of eliciting prior understanding. [Teacher Practitioner]. The Science Teacher, 70, 56-59.

Garet, M. S., Porter, A. C., Desimone, L., Birman, B. F., \& Yoon, K. S. (2001). What makes professional development effective? Results from a National Sample of Teachers. American Educational Research Journal, 38, 915-945. doi:10.3102/00028312038004915

Guskey, T. R. (2003). What makes professional development effective? Phi Delta Kappan, 84, 748-749.

Horizon Research (2002). Inside the classroom interview protocol. URL (last checked 2 January 2013).

http://www.horizon-research.com/insidetheclassroom/instruments/ob s.php

Johnston, K. (1991). High school science teachers; conceptualisations of teaching and learning: Theory and practice. European Journal of Teacher Education, 14, 65-78. doi:10.1080/0261976910140108

Karplus, R. (1977). Science teaching and the development of reasoning. Journal of Research in Science Teaching, 14, 169-175. doi:10.1002/tea.3660140212

Kelly, G. J. (2007). Discourse in science classrooms. In S. K. Abell, \& N. G. Lederman (Eds.), Handbook of research on science education. Mahwah, NJ: Lawrence Erlbaum Associates.

Llewellyn, D. (2005). Teaching high school science through inquiry: A case study approach. Thousand Oaks, CA: NSTA Press \& Corwin Press.

Loucks-Horsley, S., Love, N., Stiles, K. E., Mundry, S., \& Hewson, P. W. (2003). Designing professional development for teachers of science and mathematics. Thousand Oaks, CA: Corwin Press, Inc.

Luft, J., Bell, R. L., \& Gess-Newsome, J. (2008). Science as inquiry in the secondary setting. Arlington, VA: National Science Teachers Association. doi:10.1111/j.1475-682X.2008.00238.x

Lumpe, A. T., Haney, J. J., \& Czerniak, C. M. (2000). Assessing teachers' beliefs about their science teaching context. Journal of Research in Science Teaching, 37, 275-292. doi:10.1002/(SICI)1098-2736(200003)37:3<275::AID-TEA4>3.0.C $\underline{0 ; 2-2}$

Marshall, J. C., Horton, B., Igo, B. L., \& Switzer, D. M. (2009). K-12 science and mathematics teachers' beliefs about and use of inquiry in the classroom. International Journal of Science and Mathematics Education, 7, 575-596. doi:10.1007/s10763-007-9122-7

Marshall, J. C., Horton, B., \& Smart, J. (2009). 4E $\times 2$ instructional model: Uniting three learning constructs to improve praxis in science and mathematics classrooms. Journal of Science Teacher Education, 20, 501-516. doi:10.1007/s10972-008-9114-7

Marshall, J. C., Horton, B., Smart, J., \& Llewellyn, D. (2008). EQUIP: Electronic quality of inquiry protocol. URL (last checked 2 January 2013). http://www.clemson.edu/iim

Marshall, J. C., Smart, J., \& Horton, R. M. (2010). The design and validation of EQUIP: An instrument to assess inquiry-based instruction. International Journal of Science and Mathematics Education, 8, 299-321. doi:10.1007/s10763-009-9174-y

Marshall, J. C., Smart, J., Lotter, C., \& Sirbu, C. (2011). Comparative analysis of two inquiry observational protocols: Striving to better understand the quality of teacher facilitated inquiry-based instruction. School Science and Mathematics, 111, 306-315. doi:10.1111/j.1949-8594.2011.00091.x

Marzano, R. J. (2006). Classroom assessment and grading that work. Alexandria, VA: ASCD.

Marzano, R. J., Pickering, D. J., \& Pollock, J. E. (2001). Classroom instruction that works: Research-based strategies for increasing student achievement. Alexandria, VA: ASCD.

McDonald, S., Criswell, B., \& Dreon, O. (2008). Inquiry in the chemistry classroom: Perplexity, model, testing, and synthesis. In J. Luft, R. L. Bell, \& J. Gess-Newsome (Eds.), Science as inquiry in the secondary setting. Arlington, VA: National Science Teachers Association.

Mellado, V. (1998). The classroom practice of preservice teachers and their conceptions of teaching and learning science. Science Education, 82, 197-214.

doi:10.1002/(SICI)1098-237X(199804)82:2<197::AID-SCE5>3.0.C O;2-9

Merriam, S. B. (1998). Qualitative research and case learning applications in education. San Francisco: Jossey-Bass.

Moje, E. B. (1995). Talking about science: An interpretation of the effects of teacher talk in a high school classroom. Journal of Research in Science Teaching, 32, 349-371. doi:10.1002/tea.3660320405

Morge, L. (2005). Teacher-pupil interaction: A study of hidden beliefs in conclusion phases. International Journal of Science Education, 27, 935-956. doi:10.1080/09500690500068600

Mortimer, E. F., \& Scott, P. H. (2003). Meaning making in secondary science classrooms. Maidenhead: Open University Press.

Moscovici, H., \& Holdlund-Nelson, T. (1998). Shifting from activitymania to inquiry. Science and Children, 35, 14-17.

National Board for Professional Teaching Standards (2006). Making a difference in quality teaching and student achievement. URL (last checked 23 October 2006). http://www.nbpts.org/resources/research

National Research Council (1996). National science education standards. Washington DC: National Academies Press.

National Research Council (2000). Inquiry and the national science education standards: A guide for teaching and learning. Washington DC: National Academies Press.

Pajares, F. (1996). Self-efficacy beliefs in academic settings. Review of Educational Research, 66, 543-578. doi:10.3102/00346543066004543 


\section{J. C. MARSHALL, J. B. SMART}

Sawada, D., Piburn, M., Turley, J., Falconer, K., Benford, R., Bloom, I., \& Judson, E. (2000). Reformed teaching observation protocol (RTOP). Tempe, AZ: Arizona State University.

Schmidt, W. H., McNight, C. C., \& Raizen, S. A. (2002). A splintered vision: An investigation of US science and mathematics education. URL (last checked 2 January 2013).

http://lsc-net.terc.edu/do/conference_material/6783/show/use_set-ot h_pres.html

Smylie, M. A., Allensworth, E., Greenberg, R. C., Harris, R., \& Luppescu, S. (2001). Teacher professional development in Chicago: Supporting effective practice: Consortium on Chicago School Research.

Stiggins, R. (2005). From formative assessment to assessment for learning: A path to success in standards-based schools. Phi Delta Kappan, 87, 324-328.

Strauss, A., \& Corbin, J. (1998). Basics of qualitative research: Techniques and procedures for developing grounded theory. Thousand Oaks, CA: SAGE Publications.

Supovitz, J. A., \& Turner, H. (2000). The effects of professional development on science teaching practices and classroom culture. Journal of Research in Science Teaching, 37, 963-980. doi:10.1002/1098-2736(200011)37:9<963::AID-TEA6>3.0.CO;2-0

Van Driel, J. H., Beijaard, D., \& Verloop, N. (2001). Professional development and reform in science education: The role of teachers' practical knowledge. Journal of Research in Science Teaching, 38,
137-158.

doi:10.1002/1098-2736(200102)38:2<137::AID-TEA1001>3.0.CO; 2-U

Van Zee, E. H., Iwasyk, M., Kurose, A., Simpson, D., \& Wild, J. (2001). Student and teacher questioning during conversations about science. Journal of Research in Science Teaching, 38, 159-190. doi:10.1002/1098-2736(200102)38:2<159::AID-TEA1002>3.0.CO; 2-J

Vanosdall, R., Klentschy, M., Hedges, L. V., \& Weisbaum, K. S. (2007). A randomized study of the effects of scaffolded guided-inquiry instruction on student achievement in science. Paper Presented at the American Educational Research Association, Chicago, April 2007, $31 \mathrm{p}$.

White, B. Y., \& Frederiksen, J. R. (1998). Inquiry, modeling, and metacognition: Making science accessible to all students. Cognition and Instruction, 16, 3-118. doi:10.1207/s1532690xci1601_2

Wiggins, G., \& McTighe, J. (2005). Understanding by design (Expanded 2nd ed.). Alexandria, VA: ASCD.

Windschitl, M. (2008). What is inquiry? A framework for thinking about authentic scientific practice in the classroom. In J. Luft, R. L. Bell \& J. Gess-Newsome (Eds.), Science as inquiry in the secondary setting. Arlington, VA: National Science Teachers Association.

Yin, R. K. (2003). Case study research: Design and methods. Thousand Oaks, CA: Sage. 